\title{
فاعلية التعليم المبرهج في تثصيل الرياضيات لدى طلبة الصف الأول الثانوى في الأردن
}

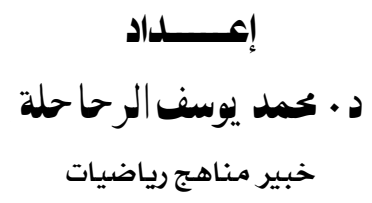

مجلة بحوث التربية النوعية - جامعة المنصورة

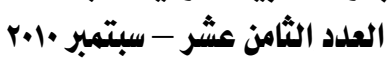




\section{فاعلية التعليم المبرهج في تهصيل

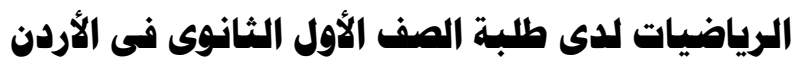

إعــداد

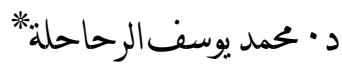

|lل|⿱一𫝀口ص

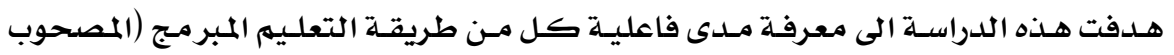

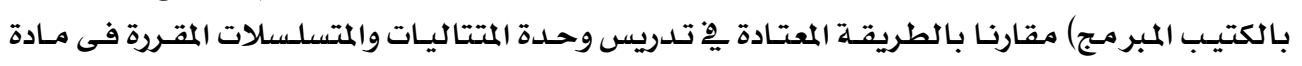
الرياضيات لطلبة الصف الاول ثانوي علمي.

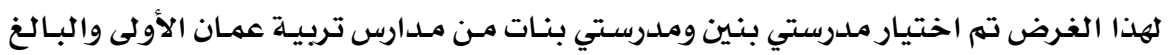

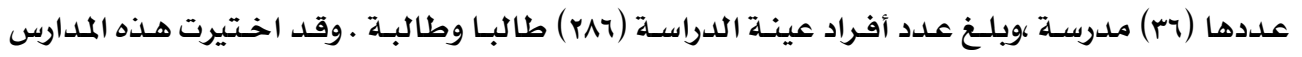

ضمن شروط معينة وتم توزيع المعالجات على الشعب لكل مدرسة بالطريقة العشوائية البسيطة.

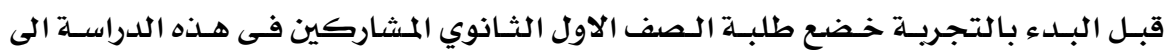

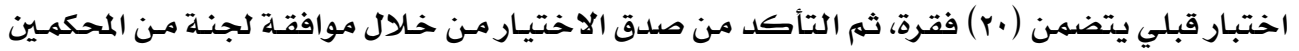

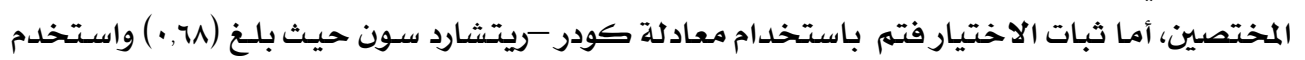

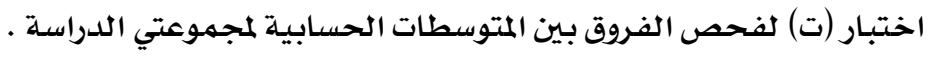

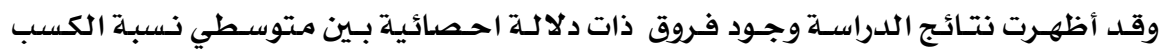

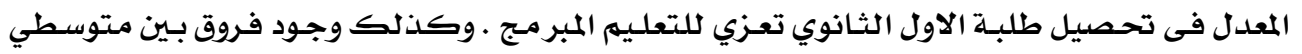

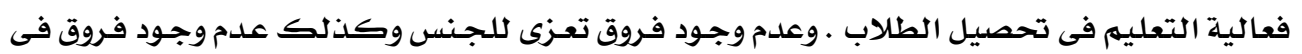

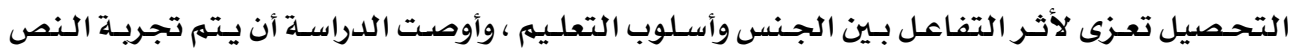

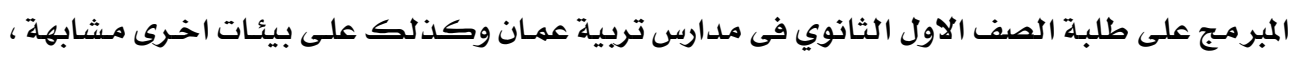

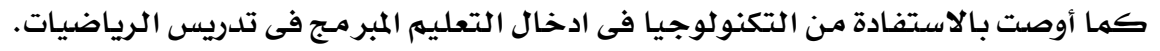




\title{
فاعلية التعليم المبرمهج فى تهصيل الرياضيات لدى طلبة الصف الأول الثانوى فى الأردن
}

\author{
إعـــاد \\ د • محمد يوسف الرحاحة:*
}

همدهمة

تنطلق أهميـة إجـراء دراسـات حـول مبـحث الرياضـيات مـن خـلال أهميـة تــريس الرياضـيات

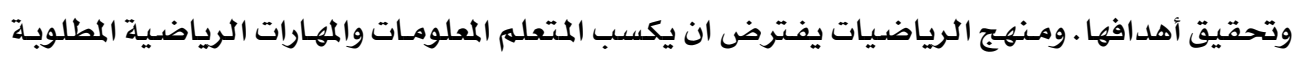

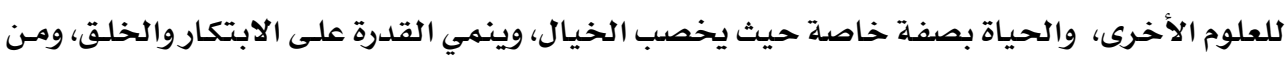

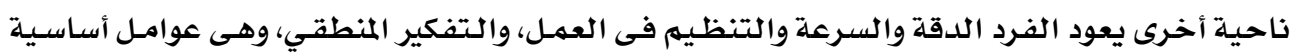
للنجاح فى الحياة.

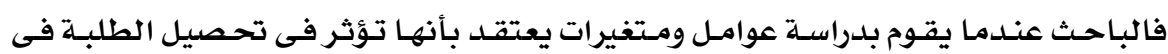

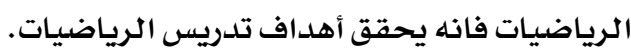
لقد واجهت التربية فى السنوات الأخيرة أزمة التزايد المستمـر فى عدد المقبلين على التعليه،

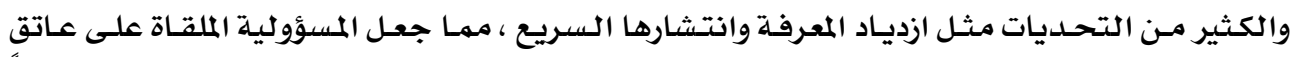

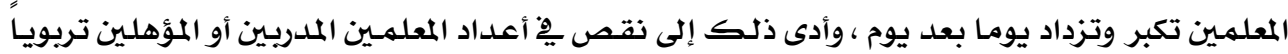

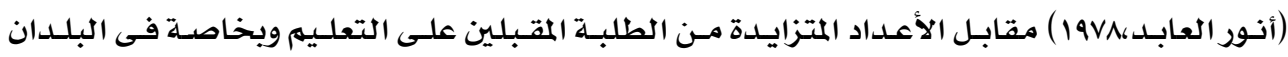
الآخذة بأسباب التقدم.

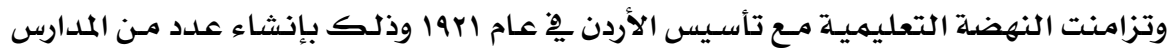

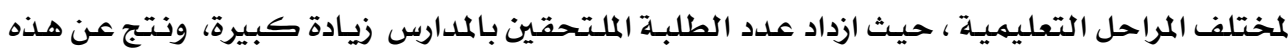

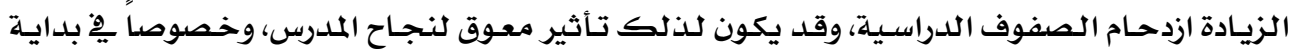

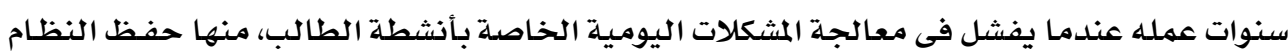

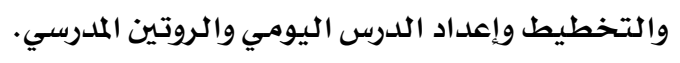

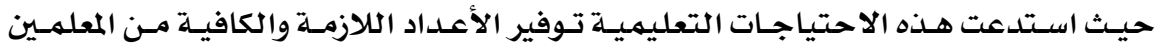

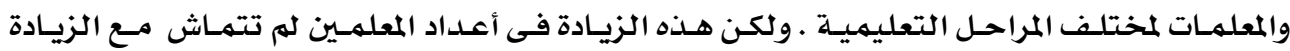

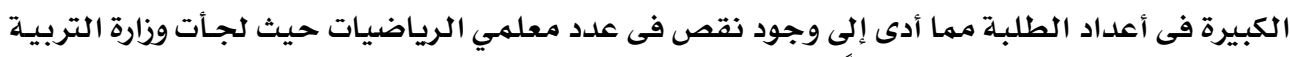

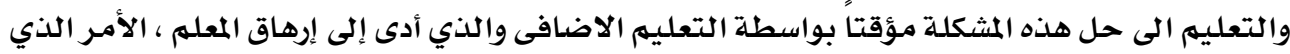

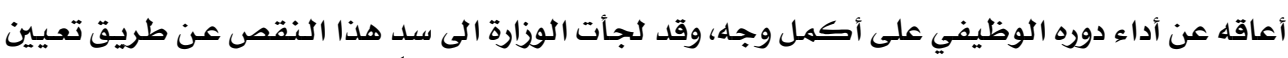

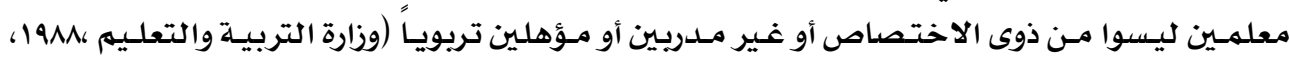

* خبير مناهج رياضيات 


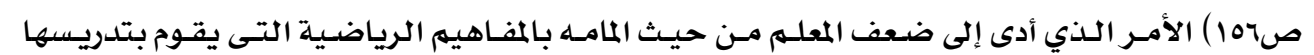

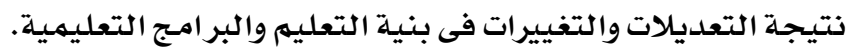

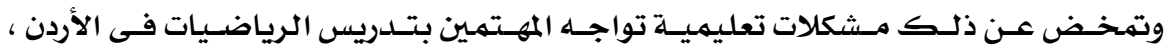

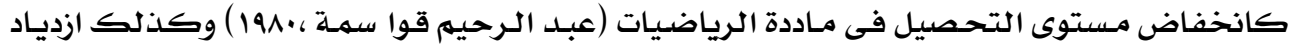

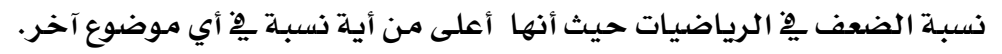
وتشكل طرق التدريس أحد العوامل الهامة التى تحدد فعالية التعليه.

والاستراتيجية الشائعة فى تلريس الرياضيات يمكن وصفها بما يلي:-

- البدء بتقديه أو إعطاء معلومات للطلبة من خلال تحركات التقديهم والعرض والتفسير ومن قبل المعلم نفسـه.

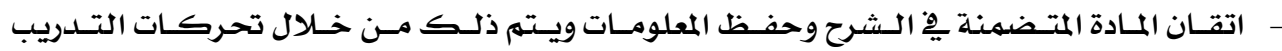

واكتسـاب المهارة من قبل الطلبـة وحل التمارين واستظهار المعلومات ( فريد ابو زينـة، ، 191) .

وأظهرت نتائج المؤتمـر الوطني الأول للتطوير التربوي الذي عقد فى عمان 191V وجود ضعف

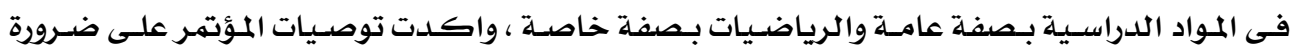

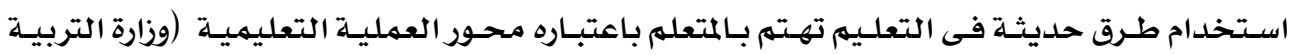

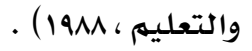

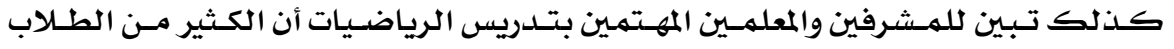
يعانون من بعض الصعوبات فى دراسـة الرياضيات فى المرحلة الثانوية بالنسبـة لبعض الموضـوعات مثل

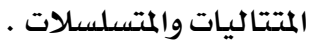

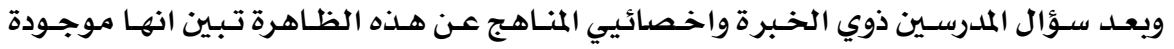
وملحوظة خلال السنوات القليلة الماضيـة مـن هنا برزت الحاجـة لاعداد وحلدة مبر مجهة تعالج مـا يعانيـه الطلبـة من صعوبات.

\section{هشكلة الدراسة وأهدافها:}

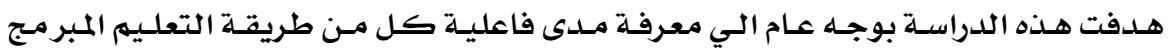

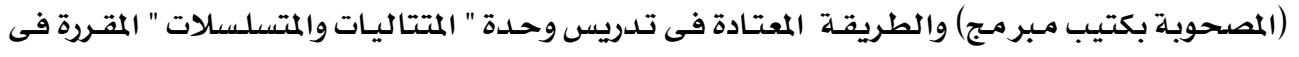

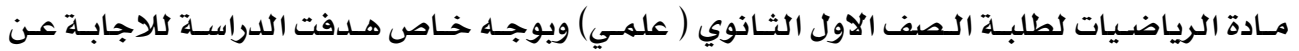
الاسئلة التالية:

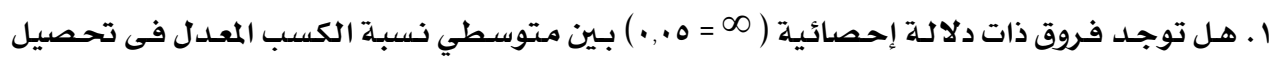

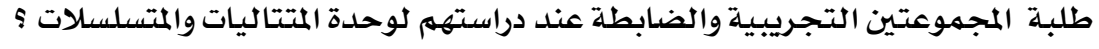

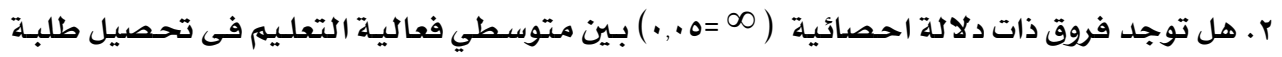

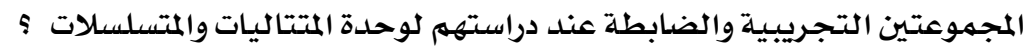




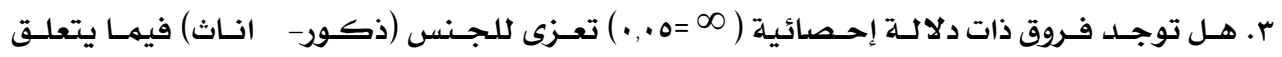

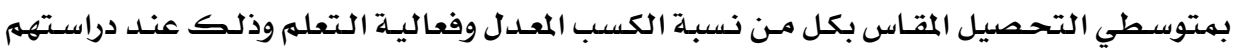

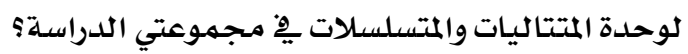

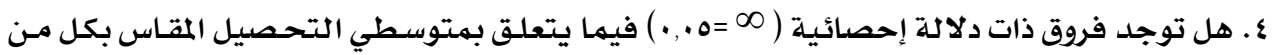

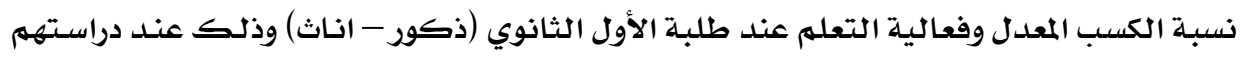

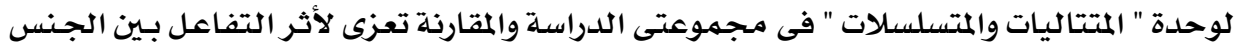

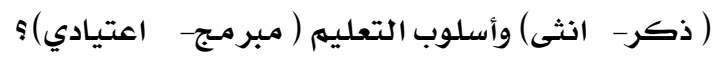

\section{فرضيات الدراسة:}

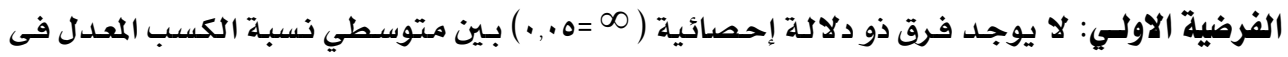

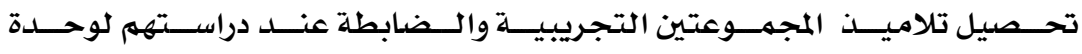

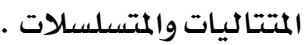
الفرضية الثانيـة: لا يوجـد فرق ذو دلالـة إحصائية (

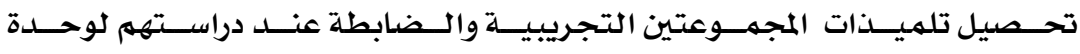

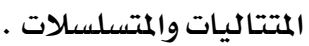

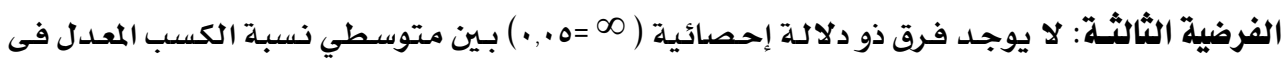

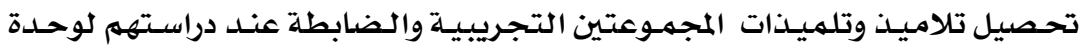
المتتاليات والمتسلسلات

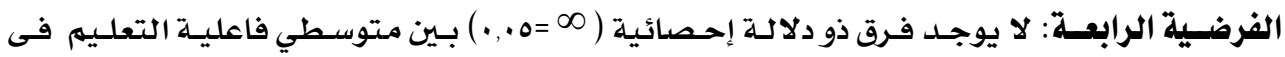

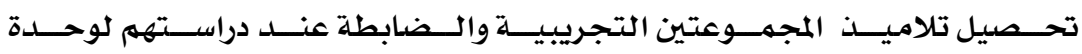

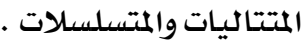

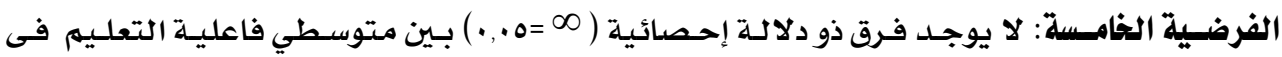

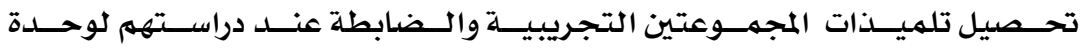

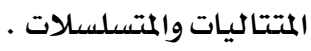

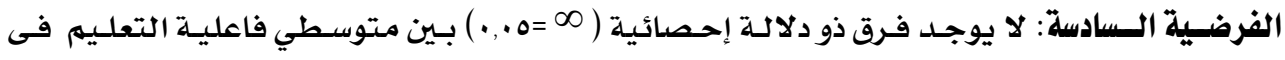
تحصيل تاميذ وتلميذات .

\section{مصطاحات الدراسة الإجرائية:}

اشتملت هذه الدراسـة على عدد من المفـاهيه والمصطلحسات التى يمكن تعريفهـا اجرائيـا على

$$
\text { التحو التالي:- }
$$

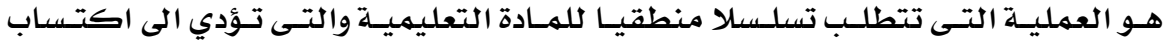

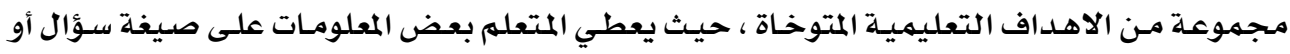


عبارة ويطلب منـه ان يجيب عن معرفته للمعلومات المقدمة اليه بدقة وبعد الانتهاء من استجابته يزود

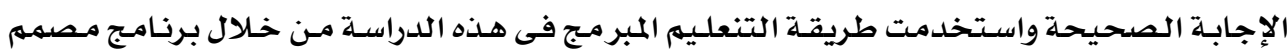

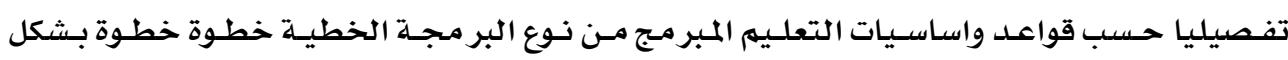

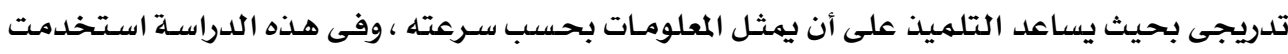

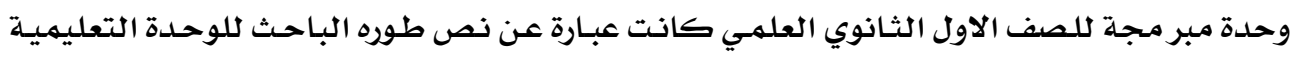

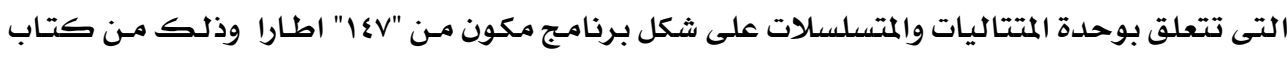

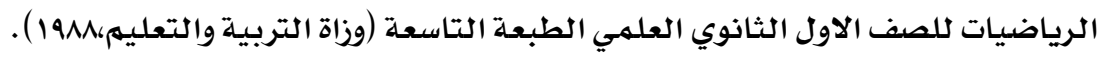

التعليه الاعتيادي:

هو نوع التعليم الذي يعتمد على عرض المادة التعليمية بعدة طرق متنوعة تشمل : المحاضرة

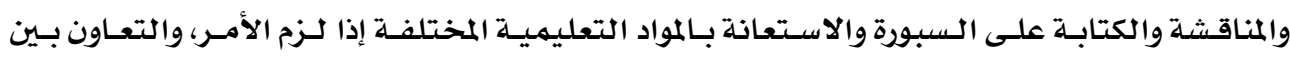

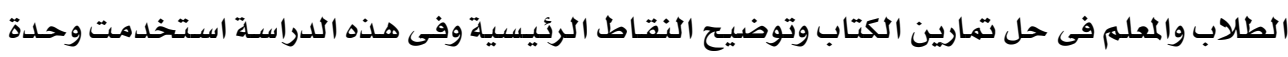

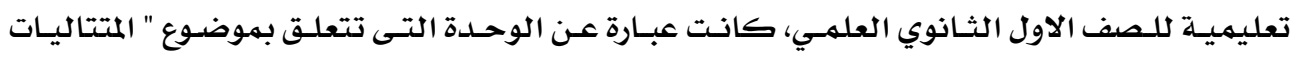

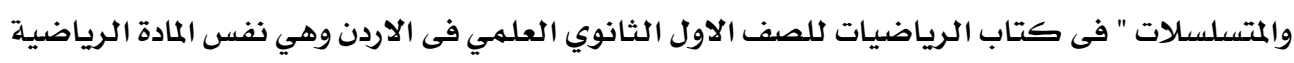

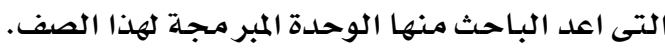

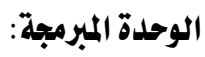

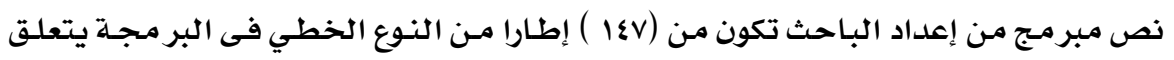

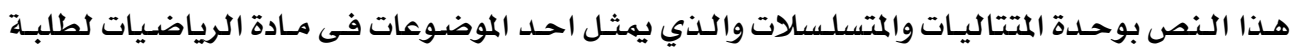

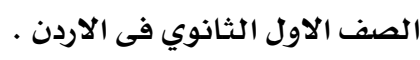

التحصيل:

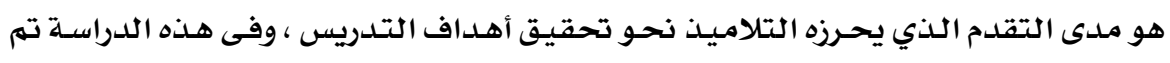

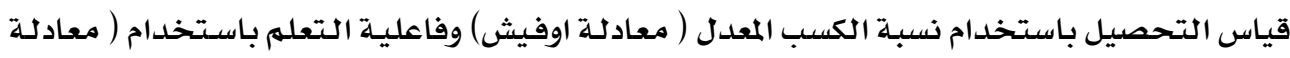

الخبرة المكتسبة ( الكسب الفعلي في التحصيل):

الفرق بين درجة الطالب فى الاختبار التحصيلي قبل دراسته للوحده وبعدها .

فاعلية التعله:

استخدم الباحث معادلة اوفيث( ) Ofiessh، 194، بسب) التالية:

$$
\text { لقياس فاعلية التعليهم = الكسب الفعلي فى التحصيل }
$$

زمن الدراسـة الحالية

والوحدة المستخدمة هى وحدة التحصيل / ساعة. 


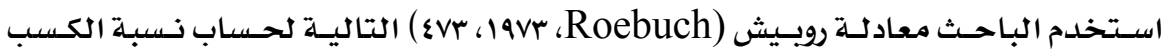

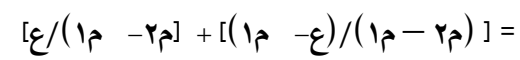

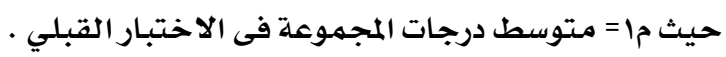

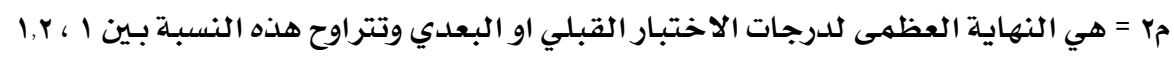

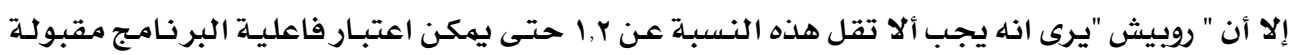

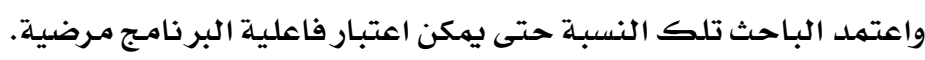

همددات الدراسة:

- اقتصرت الدراسة على وحدة دراسية واحدة هي " المتتاليات والمتسلسلات".

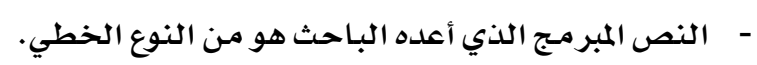

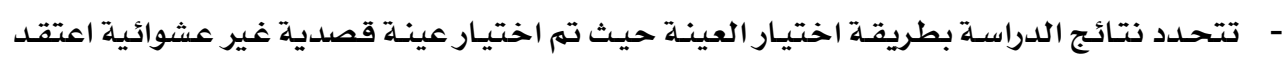
أنها تفي بغرض الدراسة.

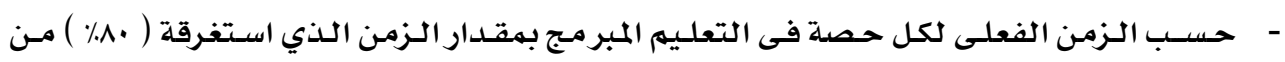

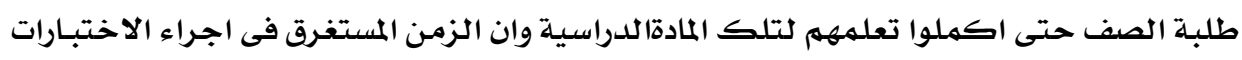

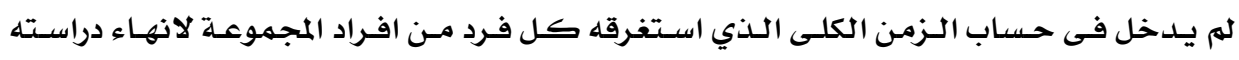
لبر لبامج.

$$
\text { - اقتصرت الدراسة على اربع مدارس ( مدرستي ذكور ومدرستي اناث) . }
$$

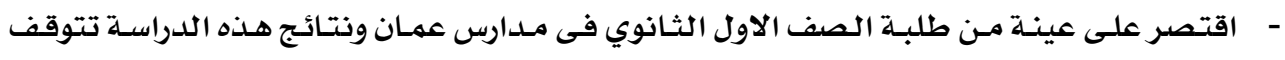

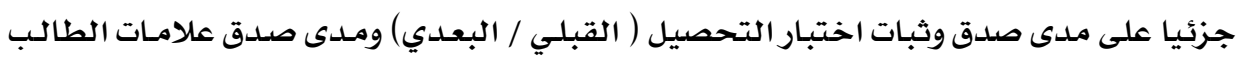

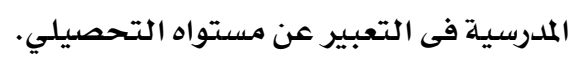

\section{الافتراضات الأساسية:}

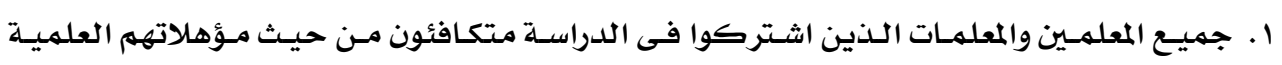

$$
\text { وقدراتهم في تدريس الرياضيات. }
$$

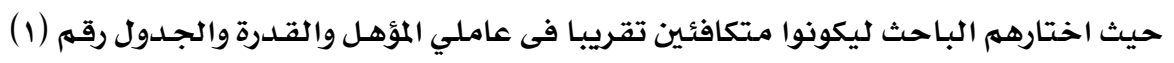

$$
\text { يوضتح ذلك. }
$$




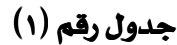

بيان التكافؤ التقريبي للمعلمين الذين قاموا باجراء التجربة

\begin{tabular}{|c|c|c|c|c|}
\hline متوسط تقديرات & سنوات & سنة & المؤهل & المدرسة \\
\hline جيد جدا & 0 & $19 \Lambda \mathrm{r}$ & بكالوريوس & توفيق ابو الهدى \\
\hline جيد جدا & $v$ & 1919 & بكالوريوس & الزبيدية الثانوية \\
\hline جيد جدا & 0 & 191^ & بكالوريوس & الجبيهة الثانوية \\
\hline جيد جدا & 0 & 1910 & بكالوريوس & روىى بنت عبد المطلب \\
\hline
\end{tabular}

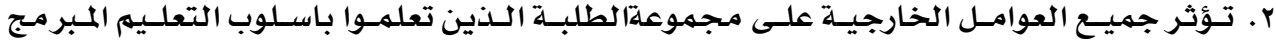

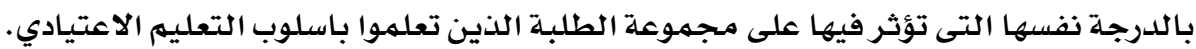

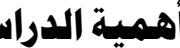

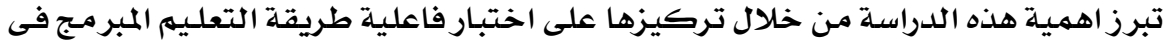

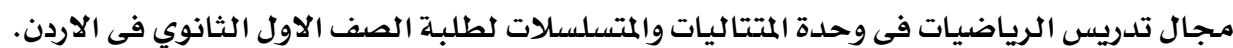
لذا فإن لهذه الدراسـة أهمية خاصدة تشمل عدة جوانب تريوية أهمها مـا يلي:ا ـ معالجـة مسشكلة الفـروق الفرديـة بـين التلاميـذ كذلك تقـدم حسلا لمشكلة تزايـد الطلبسة المستمـر

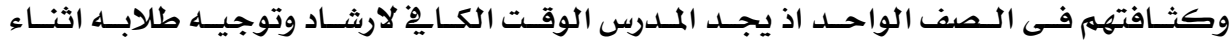

$$
\text { دراستهم الذاتية . }
$$

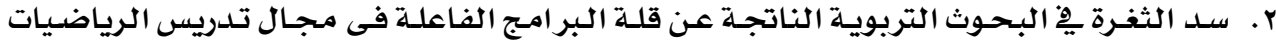

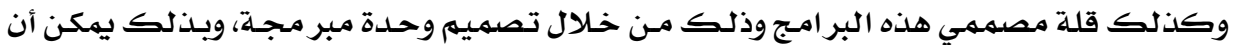

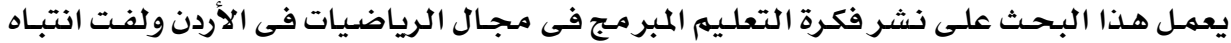

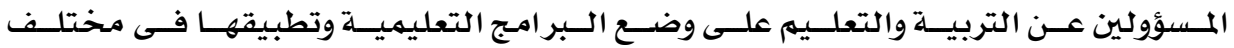

$$
\text { المراحل التدريسية . موني }
$$

r. ق قد تسهم هذه الدراسة فى توضيح مفهوم التعليهم المبر مـج وخاصسة فى مجـال تـريس الرياضيات وإمكانية تدريسله يِّ المدارس وتشجـع معلهي المدارس على استخدام هذا الأسلوب التدريسى.

\section{الدراسات السابقة: - ت الدية}

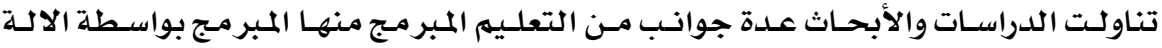

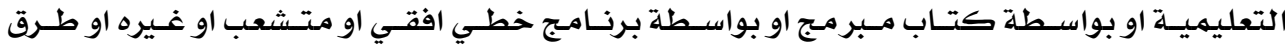

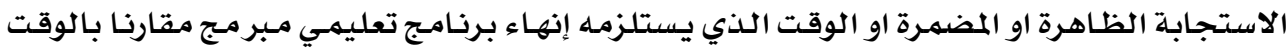

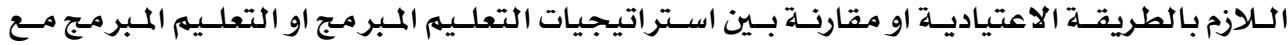
الاعتيادي لبيان مدى فاعلية كل استراتيجية. 


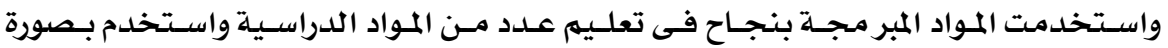

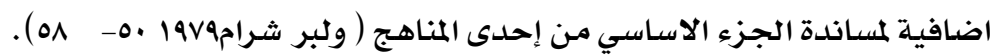

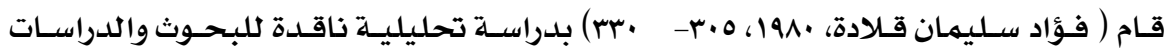

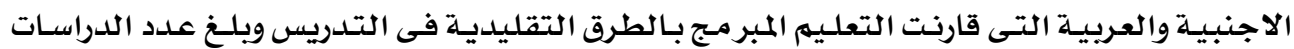

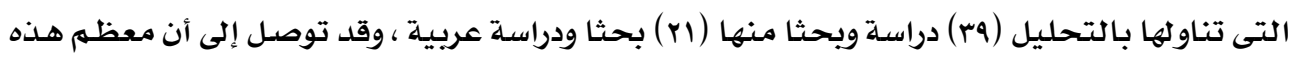

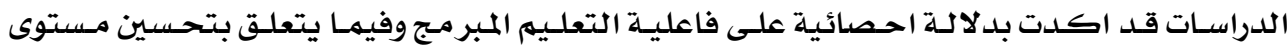

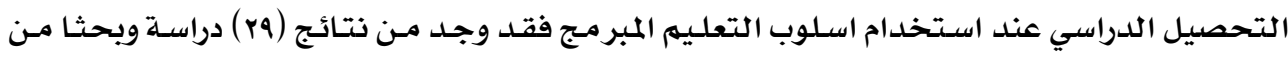

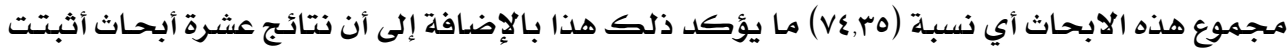

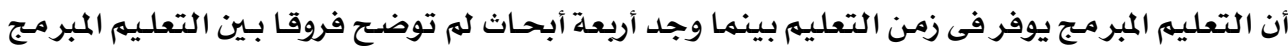

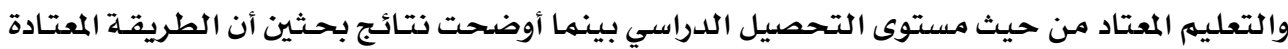
تفوق المبر مجة في التدريس.

وفى حدود معرفة البـاحث لم تجر سوى دراسـة واحدة فى الأردن لمبحثث الرياضيات ( عبـد الله

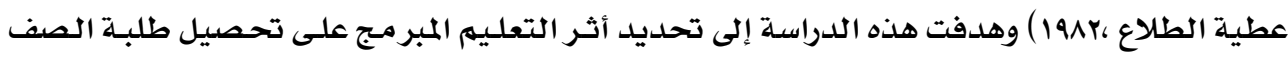

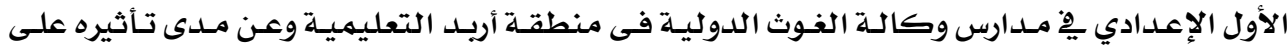
اتجاهاتهم نحو الرياضيات.

وتكونت عينـة الدراسـة مـن (rAV) طالبـا وطالبـة مـن طلبــة الصفين الاول والثـاني الاعـدادي

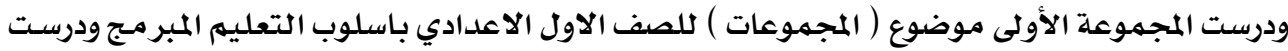

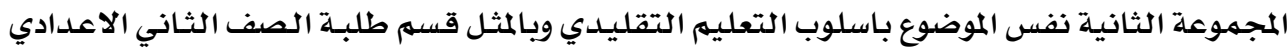
وقبل البدء بالتجربة خضع الطلبـة الى اختبار تحصيل قبلي والى اختبـار قبلي لقياس اتجاهـاتهم نحـو

الرياضيات.

ودلت نتائج الدراسـة على وجود فروق يِّات الاتجاهـات نحو الرياضيات لصالح الطلبـة ( ذكور

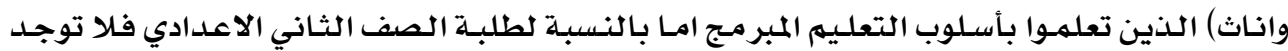
فروق ذات دلالة احصائية.

كما أن فعالية التحصيل بالتعليهم المبر مـج مـع الطلبـة مساويـة لفعاليته مـع الطالبـات لكل

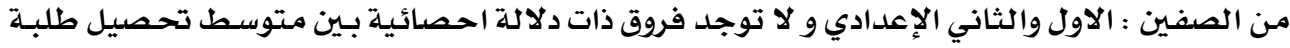

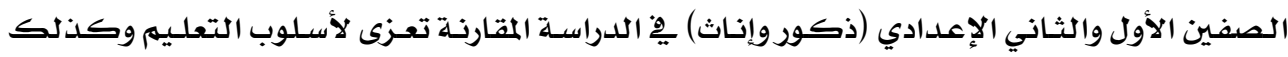

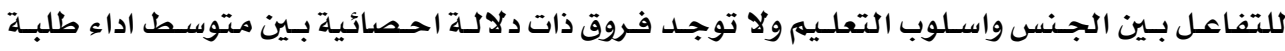

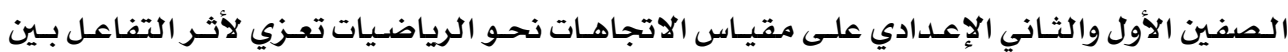

$$
\text { الجنس والتعليه البرنامجى . الجولي }
$$

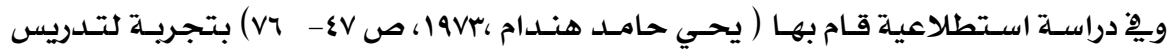

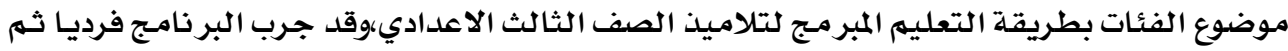


جماعيـا و أظهـرت نتـائج الدراســة تحسن مسستوى التحـصيل بالنسسبـة للطلبـة الـذين اسـتخدم معهـم

البرنامـج.

كما قام ( أحمد السيد مصطفى 19V0) بدراسـة كان الهدف منها إعـداد مقرر برنا مجي "

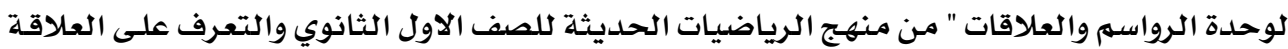

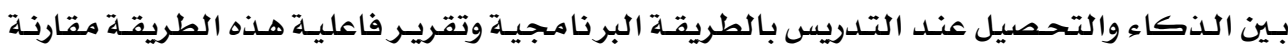

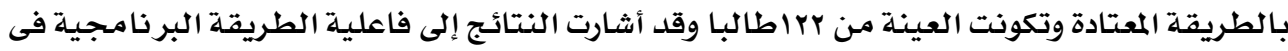

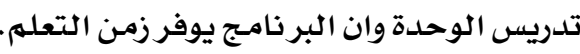

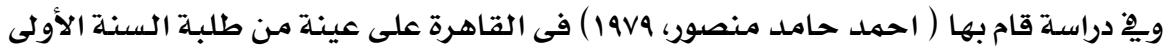

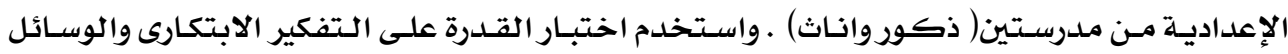

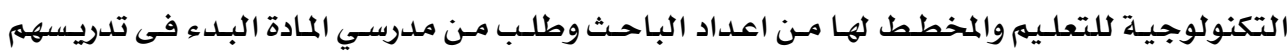

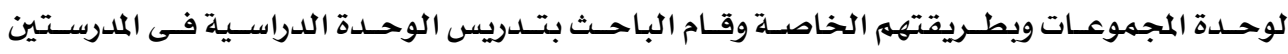

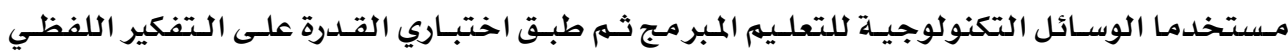

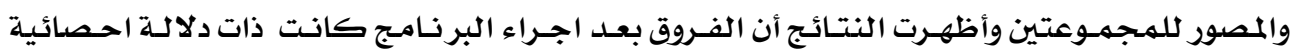

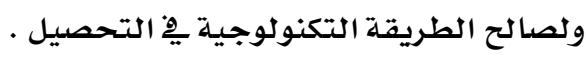

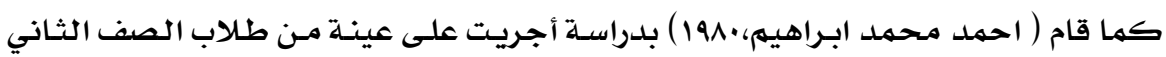

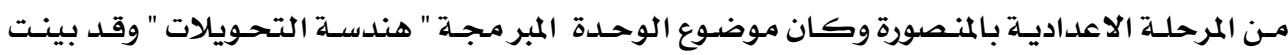

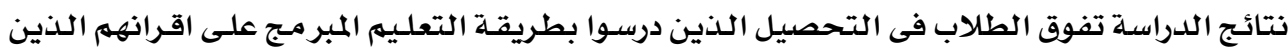
درسوا بالطريقة التقليدية.

ومن الدراسـات التي أظهرت تفـوق اسـتراتيجية التعليهم المبر مـج دراسـة ( ليلى دويغـرومـحمــ

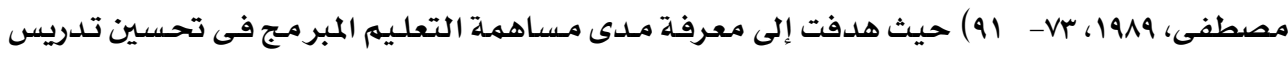

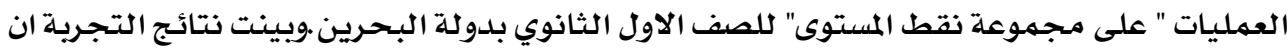

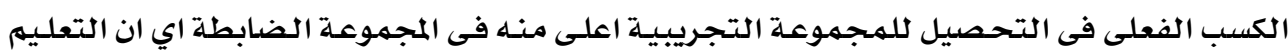
المبر م-ج يوفر الوقت لكل من المعلهم والمتعلهم.

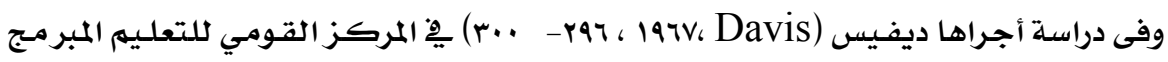

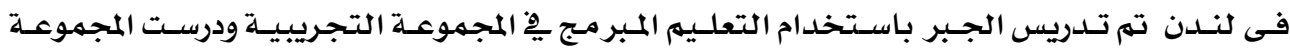

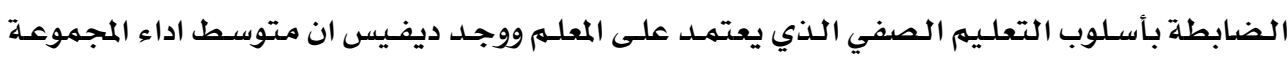

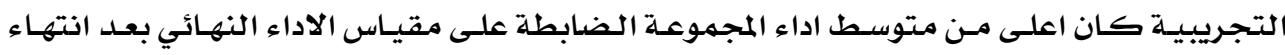
التعليهم التجرئ.

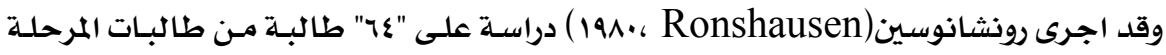
الثانوية فى تدريس موضوع الاحتمـالات فى الرياضيات . 
وأظهـرت النتـائج أن متوسـط درجـات تحـصيل الطـلاب الـذين هـم فـوق المتوسـط مـن حيـث مستوى الذكاء كانت افضل من متوسط درجات الطلاب الذين هم دون مستوى المتوسط وذلك عنـــ

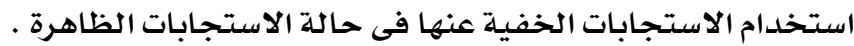

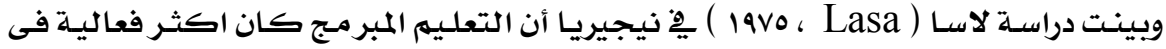

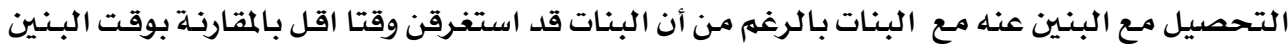
الا ان مستوى تحصيلهن كان اقل من تحصيل البنين فى الرياضيات. واشـارت دراسـة كوزمـا وآخـرين (Kozma,Etal,1978) والـتي هـدفت إلى مقارنـة النتـائج

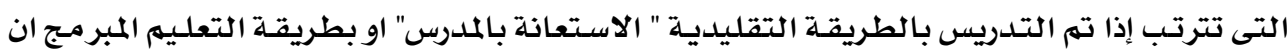

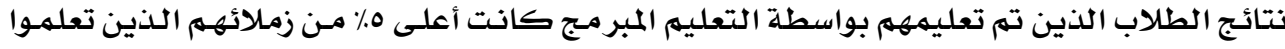

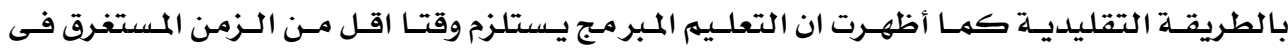
الطريقة التقليدية.

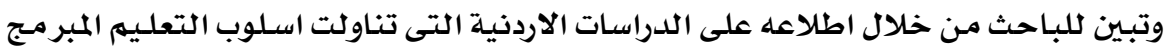

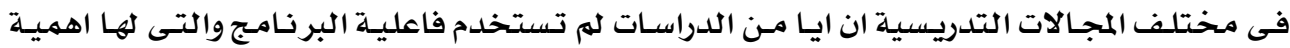

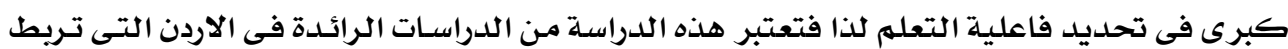

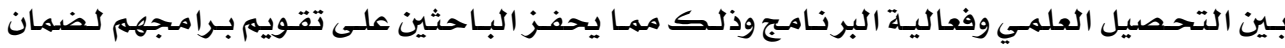
الحصول على تعله فعال.

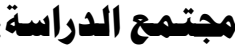

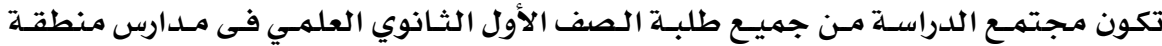

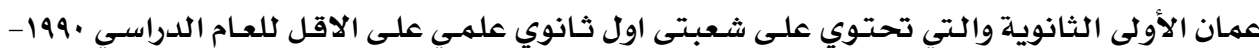

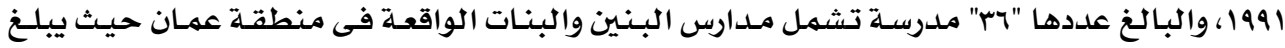

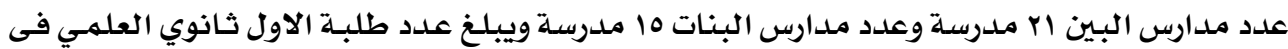

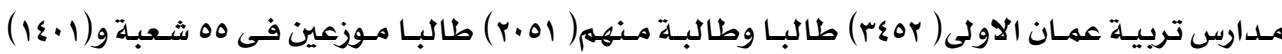

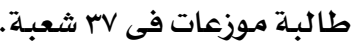
عينة الدراسة:

تم حصر المدارس فى مجتهـع الدراسة والشعب التى تتضمنها وقد تم اختيـار مدرستي بـنـين

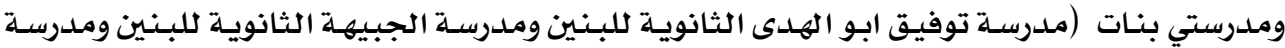

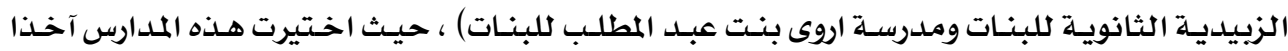

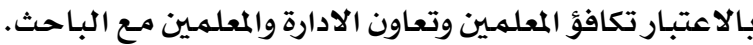

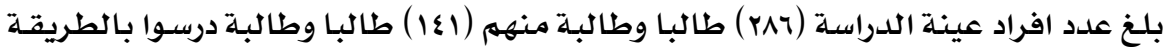

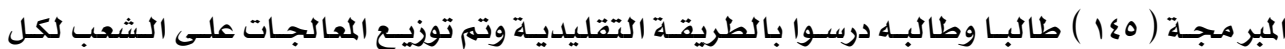

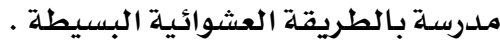




\section{1. أختبار تصميلي ( قبلي - بعلي):}

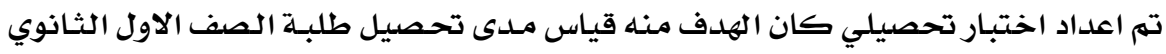

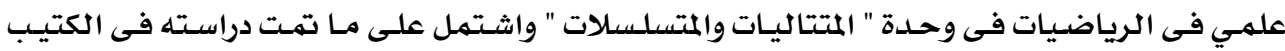

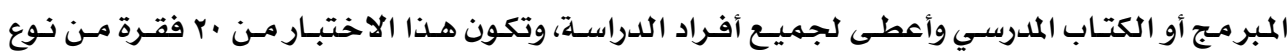
الاختيار من متعدد والخطوات التى اتبعت فى إعداد هذا الاختبار المار هي : 1 - تحديد جوانب التعلم التي يراد قياسها فى الوحدة . r - ب - وضع الأهداف التعليمية للوحدة الدراسية والتى تغطي المواقف التعليمية.

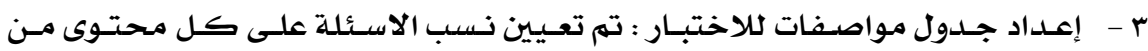
محتويات التحليل وعلى كل هدف من الاهداف ـ ملاف

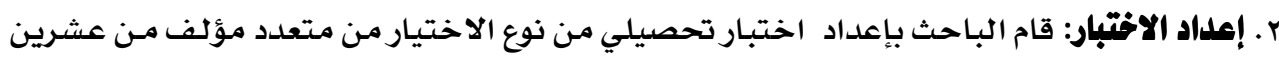

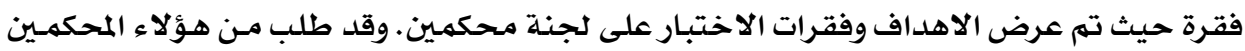

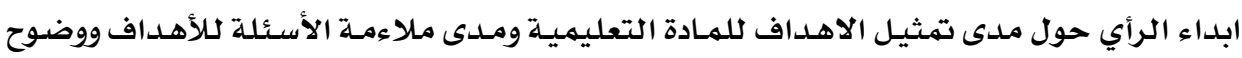

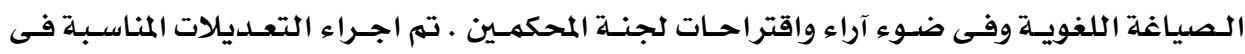

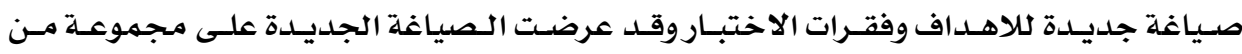

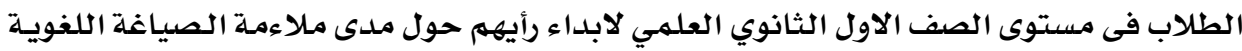

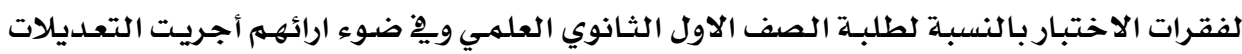

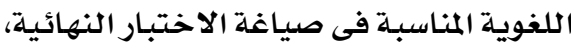

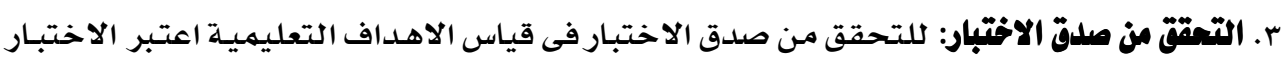
صادقا بناءا على صدق الخطوات ا، r، بـ.

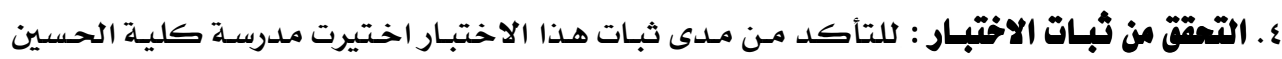

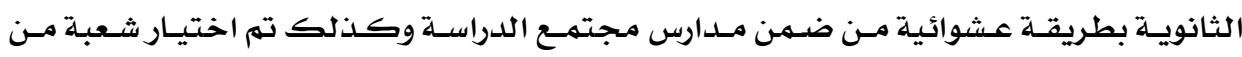

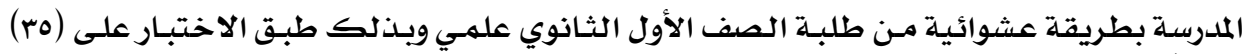

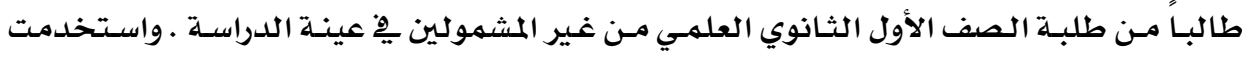

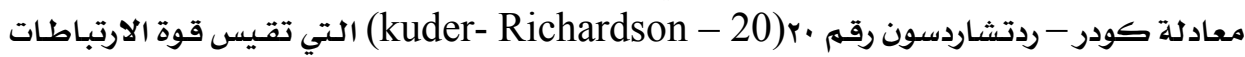

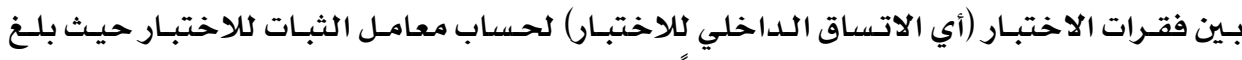

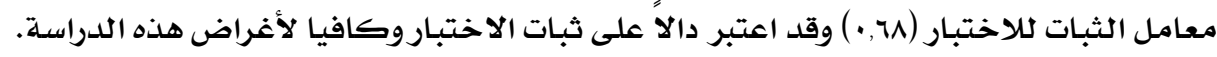

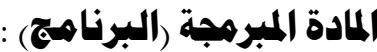

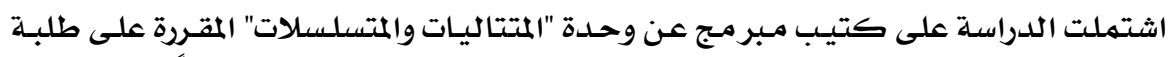

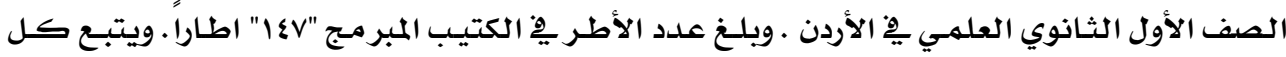

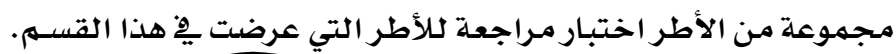




\section{وفيما يلي الخطوات المتبعة عند إعداد البرنامـج:}

أولاً : إعداد البرنامج :

قام البـاحث بدراسـة نظريـة شاملة عن التعلـيم المبر مـج وكيفـة عمل البر امـج التعليميـة مهـا

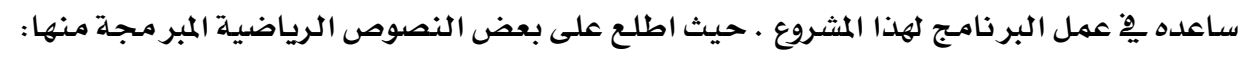
- كتاب "المجموعات" لروبرت ينج · ل

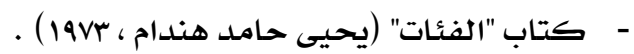

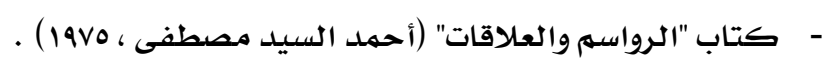

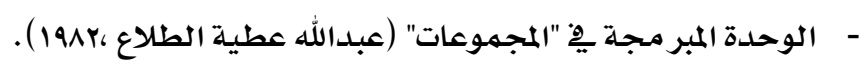

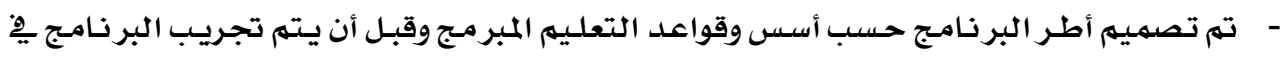

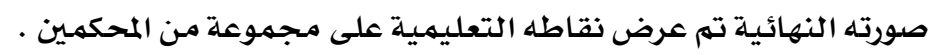

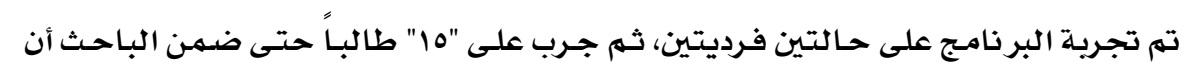

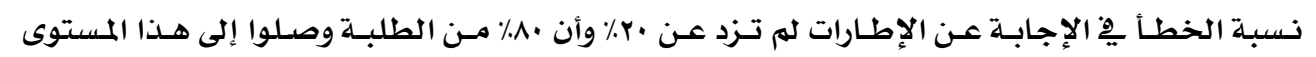

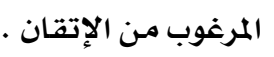

\section{ثانياً : كيفية إستخدام الكتيب المبرمج :}

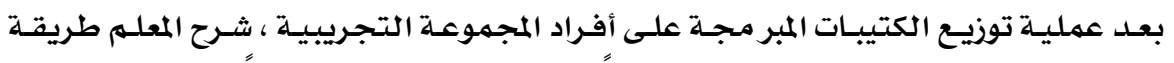

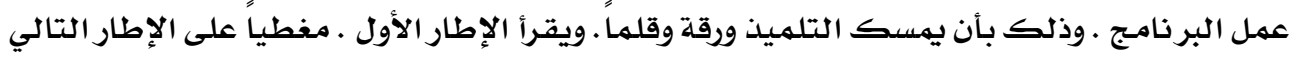

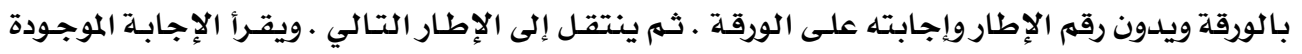

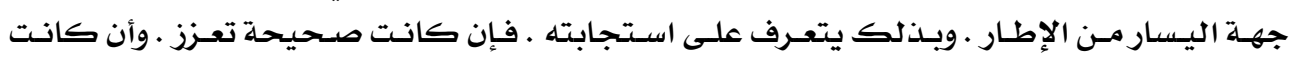

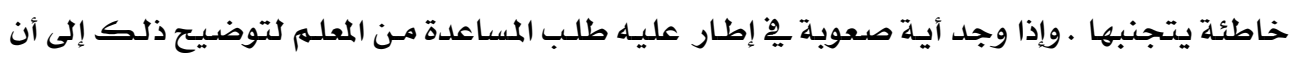

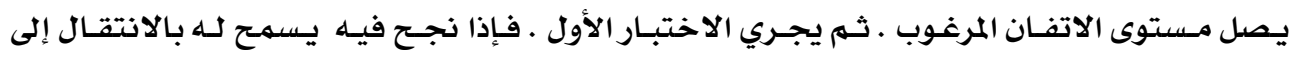

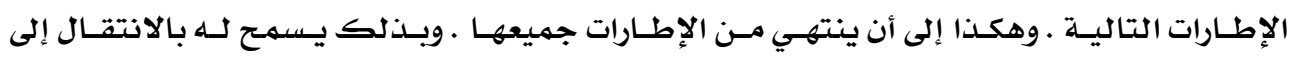

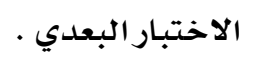

إجراءات الدراسية : أولاً : تقويم البرنامج : تم تقويهم البر نامج على مـرحلتين :

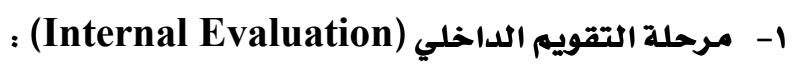

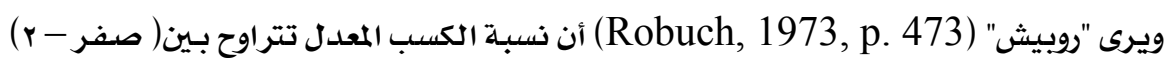
ويجب أن لا تقل عن (r, ) حتى يمكن اعتبار فاعلية البر نامج مرضية. 


\section{r- مرحلة التقويم الخارجي (External Evaluation) :}

ويقصد بـه فاعلية البر نامـج بمقارنته بغيره من الطرق أو البر امـج • وهذا يعني مقارنـة التغير

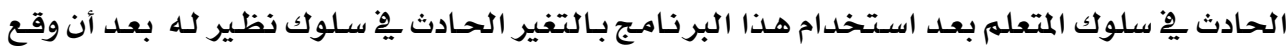

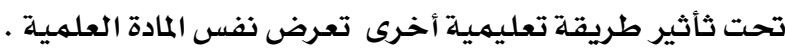

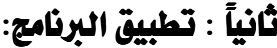

لقد تم عرض أهداف وغايات الدراسة على مديري / مديرات / ومعلمي ومعلمات المدارس المختارة . بغرض تقديم التسهيلات الكلازمـة لتطبيق الدراسـة .

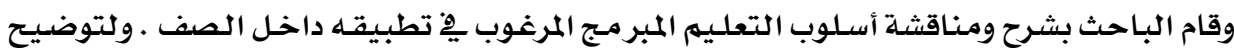

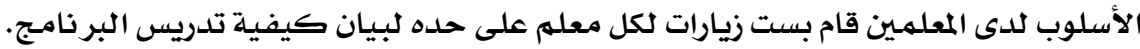

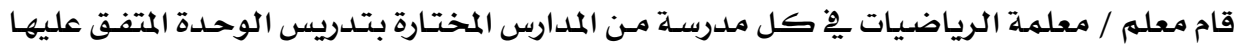
وفق الخطة التي أعدها الباحث لتلك الغاية لكل من المجمـوعتين التجريبيـة والضابطة وكانت الخطة تنسجم مـع الواقع الفعلي للصف الصف والطالب .

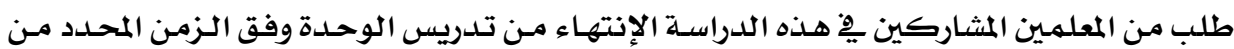

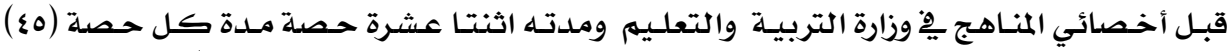

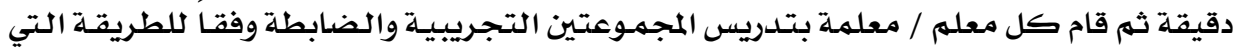
حلددها الباحث .

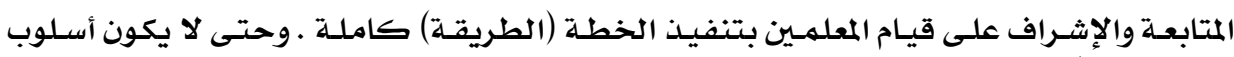

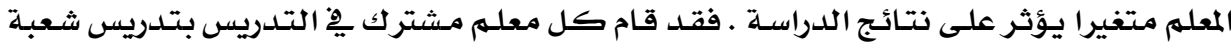

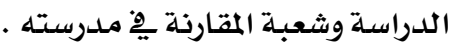
بعد انتهاء التجربة خضع الطلبـة ِِّ اليوم التالي الى اختبـار تحصيلي بعـدي وهو نفس الاختبـار

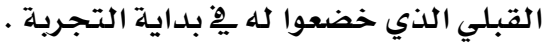

التأكد من تكافؤ المجموعتين (التجريبية والضابطة) :

للتأكـد مـن تكـافؤ المجمـوعتين التجريبيـة والضـابطة قبـل بــــ تطبيـق الدراسـة ـ اسـتخدم

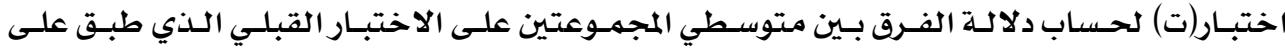
المجموعتين قبل بلدء التجريبة . ل 


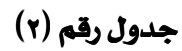

نتائج اختبار (ت) لحساب الفرق بين المتوسطين الحسابيين على المجموعتين

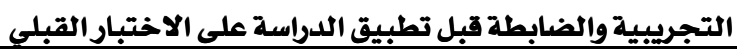

\begin{tabular}{|c|c|c|c|c|c|c|c|}
\hline لمستوى الدلالة & درجات & (ت)المحسوبة & المخطا| & الاندحراف & متوسط المجموعة & عدد الأفراد & وجه المقارنة المجموعة \\
\hline \multirow[t]{2}{*}{$\cdot, 00 Y \varepsilon$} & $r \wedge \varepsilon$ &., $09 \leqslant \wedge$ & אזדו, • & $1,94 \wedge$ & $\varepsilon, 7 Y \wedge$ & $|\leqslant|$ & المجموعة التجريبية \\
\hline & & & •, $\{Y Y \varepsilon$ & 0,017 & $\{, 91$. & $1 \leqslant 0$ & المجموعة الضابطة \\
\hline
\end{tabular}

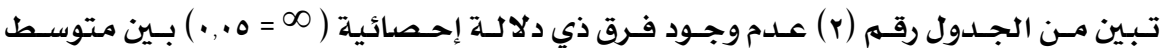

علامات الطلبـة يِ المجموعتين على الاختبار القبلي يخ وحدة المتتاليات والمتسلسلات .

\section{تصميم الدراسة :}

- - المتغير المستقل هْ هـذه الدراسـة هـو الطريقـة (اعتيـادي - مـبرمهج ) بالإضـافة إلى مـتغير تصنيفي

$$
\text { وهو الجنس (ذكر - أنثى) . }
$$

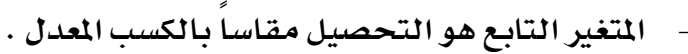

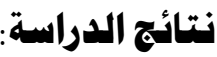

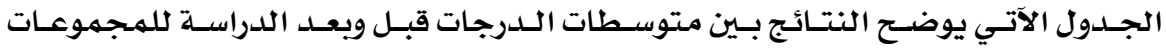

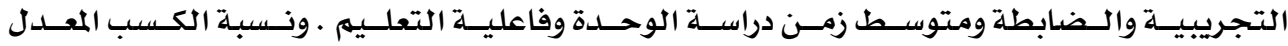

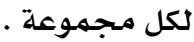

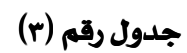

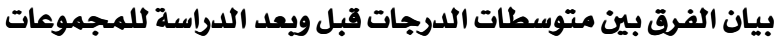

\begin{tabular}{|c|c|c|c|c|c|}
\hline نسبة الكسب & فاعلية & 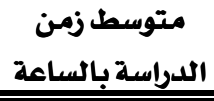 & الفرق بين متوسطات & المجموعة & المدرسة \\
\hline $\begin{array}{l}1, Y 1 \\
1, \pi r\end{array}$ & $\begin{array}{l}1,17 \\
1, V r\end{array}$ & $\begin{array}{l}9, \mathrm{r} \\
\Lambda, \cdot \cdot\end{array}$ & $\begin{array}{l}1 \cdot, v 9 \\
17,91\end{array}$ & بنين ضابطة بنين & توفيق أبو الهدى \\
\hline $\begin{array}{l}1, \cdot V \\
1,09\end{array}$ & $\begin{array}{l}1, \cdot r \\
1, V \Lambda\end{array}$ & $\begin{array}{l}9, r r \\
\Lambda, \cdots\end{array}$ & $\begin{array}{l}9,0 r \\
|\varepsilon, r|\end{array}$ & بنات بنات ضابطة & الزييدية \\
\hline $\begin{array}{l}\cdot, \text { TV } \\
1, r \varepsilon\end{array}$ & $\begin{array}{l}\cdot, \vee \vee \\
1, \varepsilon 7\end{array}$ & $\begin{array}{ll}\Lambda, \cdots \\
V, r \varepsilon\end{array}$ & $\begin{array}{l}0, r V \\
1 \cdot, V r\end{array}$ & بنبن بن ضـابطة & الجبيهة \\
\hline $\begin{array}{l}\cdot, T \\
, Y Y\end{array}$ & $\begin{array}{l}\cdot, V Y \\
1, \varepsilon \varepsilon\end{array}$ & $\begin{array}{l}\wedge, \cdots \\
v, r \varepsilon\end{array}$ & $\begin{array}{l}0, V r \\
1 \cdot, 07\end{array}$ & بنـات ضـن تجربيبية & عبدالروى بنت \\
\hline
\end{tabular}

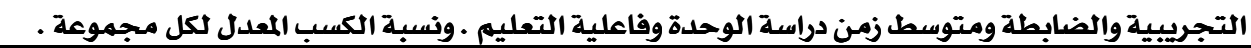


جدول رقم (£)

بيان الفرق بين الذكوروالإناث والجنسين معاً وطريقة التعليم والعدد ونسبة الكسب المعدل وفاعلية التعليم

\begin{tabular}{|c|c|c|c|c|}
\hline فاعلية & نسبة الكسب & العلدد & المجمهوعة & وجها المقارنة \\
\hline $\begin{array}{l}1,171 \\
.911\end{array}$ & $\begin{array}{l}1,0 . r \\
., 911\end{array}$ & $\begin{array}{l}77 \\
61\end{array}$ & تجريبي & ذكور \\
\hline $\begin{array}{l}1,17 Y \\
\cdot, \wedge 7 V\end{array}$ & $\begin{array}{l}1, \& Y \wedge \\
\cdot, \wedge \vee Y\end{array}$ & $\begin{array}{l}\text { vo } \\
\text { v\& }\end{array}$ & تجريبي & إناث \\
\hline
\end{tabular}

يتضح من الجدول رقم (ع) أن :

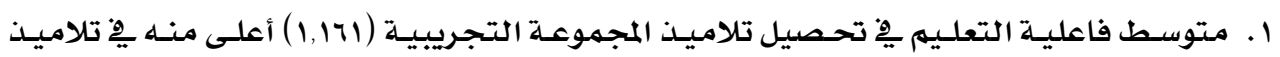

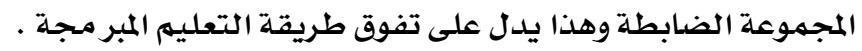

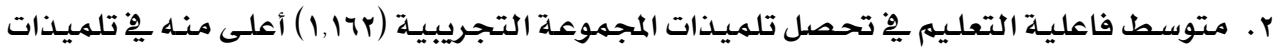

المجموعة الضابطة (NTV, • ) وهذا يدل على تفوق طريقة التعليهم المبر مجلة .

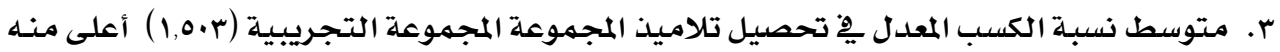

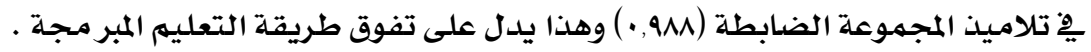

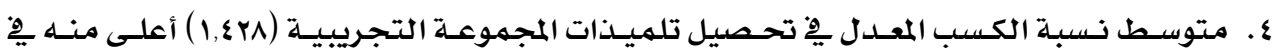

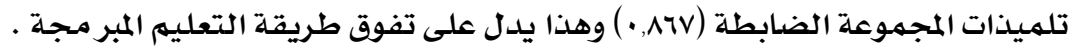

كها يتضح أن متوسط نسبـة الكسب المعـدل يِّ المجموعة التجريبيـة أكبر مـن (r, ) وهـذا

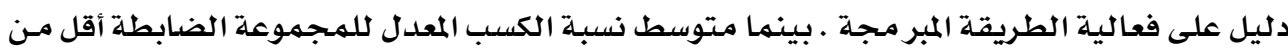

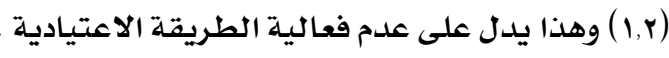

تم التأكد مـن دلالات هذه الفروق احصائياً باستخدام اختبار تحليل التباين (r×r) .

$$
\text { جدول رقم (0) }
$$

نتائج التباين (Y×r) للعلامات على الاختبار بحساب نسبة الكسب المعدل يو التحصيل

\begin{tabular}{|c|c|c|c|c|c|}
\hline مستوى الدلادة & $\begin{array}{c}\text { المحسوبة } \\
\text { (ف) }\end{array}$ & متوسط مريع الانحرافات & درجة الحرية & مجموع مريع الانحرا ف & مصدر التباين \\
\hline$\cdot, \cdots 1$ & $11 \leqslant, 07$ & r., YOYA & 1 & r.,YOYA & الطريقة \\
\hline$\cdot .719$ & $r, 01$ & $\cdot, 7 r \cdot 9$ & 1 & $\cdot, \pi r \cdot 9$ & الجنس \\
\hline \multirow[t]{3}{*}{$\cdot, V \cdot \wedge \mathrm{V}$} & $\cdot, 1 \varepsilon$ & $\cdot, .0 \leqslant \Lambda$ & 1 & $\cdot, r \leqslant \Lambda$ & الطريقة × الجنس \\
\hline & & $\cdot$, IVTV & rAY & $\{9, \wedge 0 \leqslant 1 \%$ & الخطأ \\
\hline & & $\cdot, Y \leqslant \wedge 1$ & rAO & $v \cdot, v 1 \cdots r$ & الكلى \\
\hline
\end{tabular}




\section{يتضح من الجدول رقم (0) :}

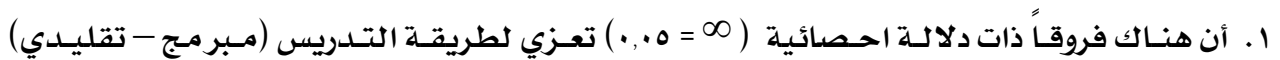

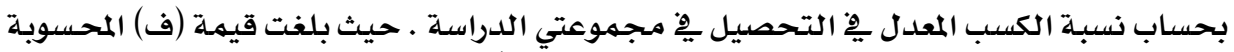

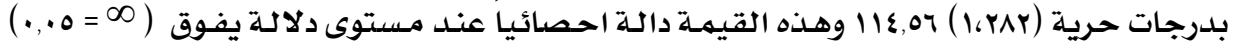

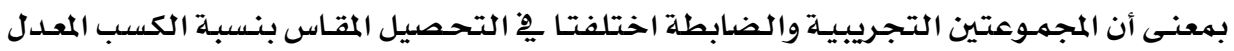

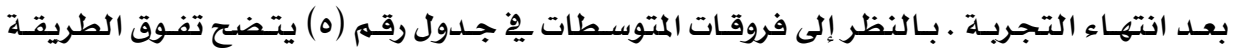

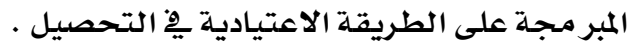

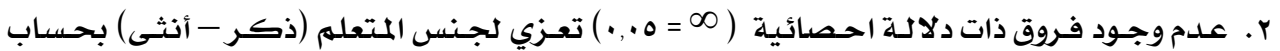

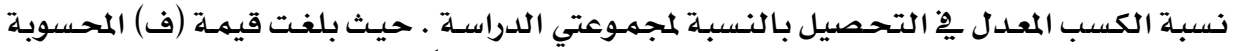

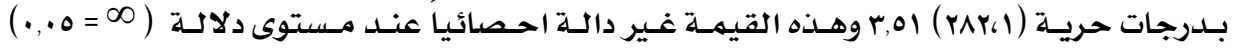

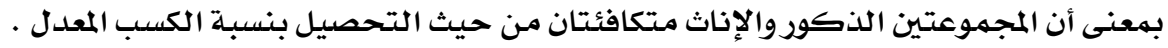

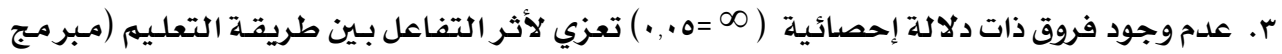

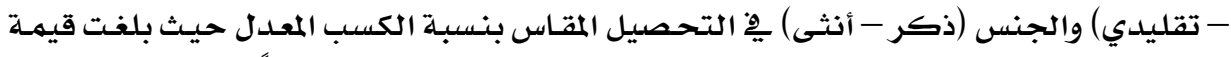

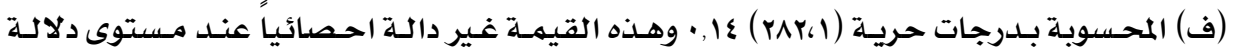

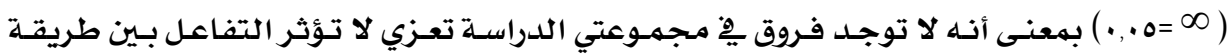

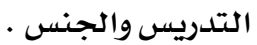

\section{جدول رقم (؟)}

نتائج تحليل التباين (Y×Y) للعلامات على الاختبار بحساب فاعلية التعلم هِ التحصيل

\begin{tabular}{|c|c|c|c|c|c|}
\hline مستوى الدلانة & $\begin{array}{c}\text { (ف) } \\
\text { المحسوبة }\end{array}$ & متوسط مريع & درجة & مجموع مريع & مصدر التباين \\
\hline$* \cdot, \cdots+$ & IVY,O0 & $r q, \cdot \xi r r$ & 1 & $r q, \cdot \sum r r$ & الطريقة \\
\hline$\cdot, 7 \leqslant 97$ & $\cdot, Y_{1}$ & $\cdot, \cdot \varepsilon 7 \Lambda$ & 1 & $\cdot, \cdot \varepsilon \pi$ & الجنس \\
\hline \multirow[t]{3}{*}{ - V01 } & $\cdot, 1$. & •, TYM & 1 & $\cdot$, YYA & الطريقة × الجنس \\
\hline & & • & rAY & $T r, \Lambda \cdot V$. & الخطأ \\
\hline & & סודא, & Y^O & I.r.r.r.T & الكلي \\
\hline
\end{tabular}

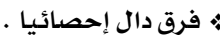

\section{يتضح من الجدول رقم (ج) :}

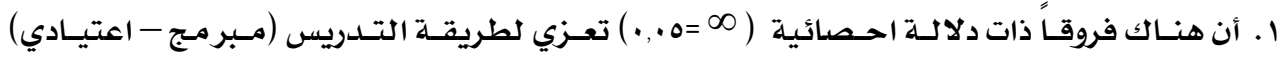

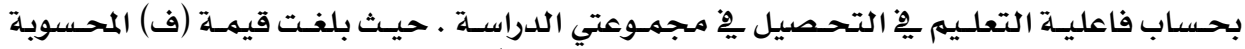

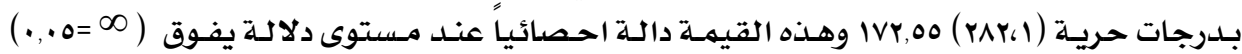

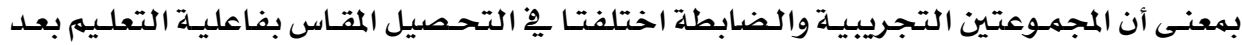




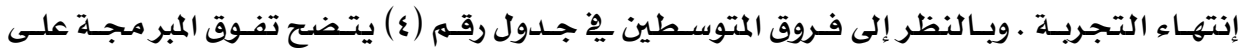
الطريقة الاعتيادية يِّن التحصيل.

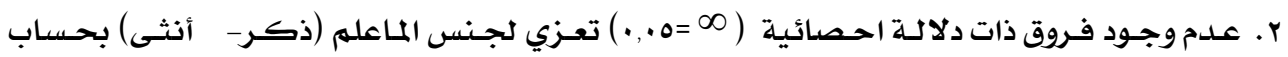

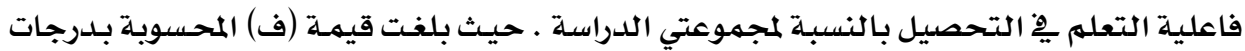

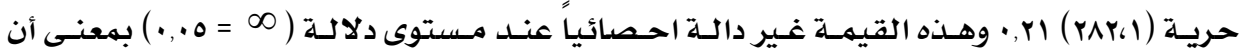

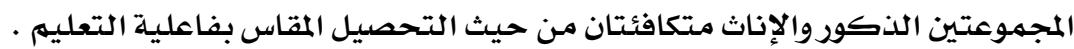

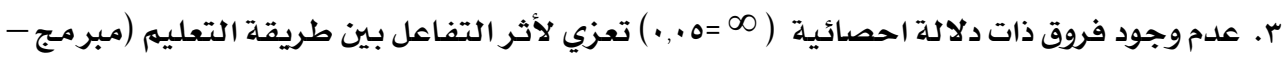

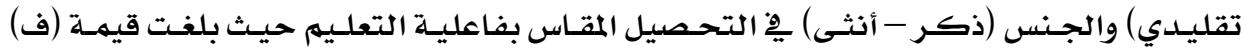

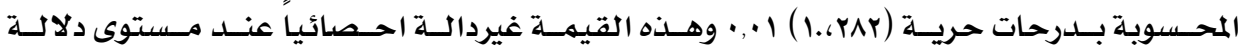

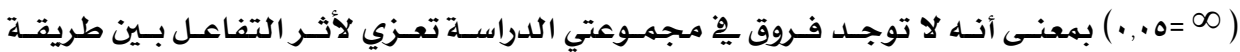
التدريس والجنس يِّ التحصيل المقاس بفاعلية التعليه.

ومما يجدر الإثـارة اليه أن هذه النتائج السابقة يجب أن تؤخذ بحذر فلقد يعزي تفوق طلبة

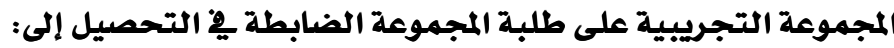

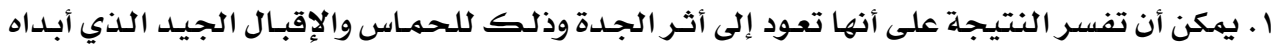

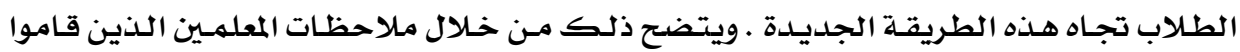

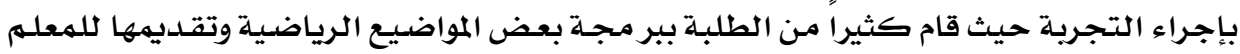

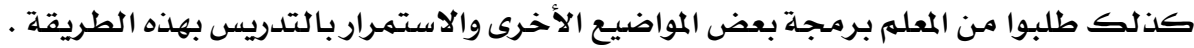

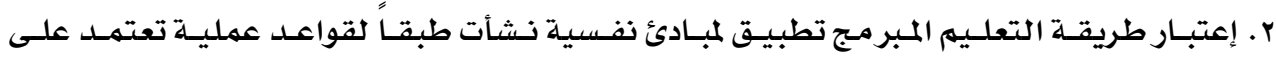

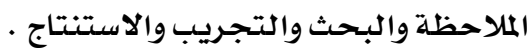

\section{استنتاجات الدراسة}

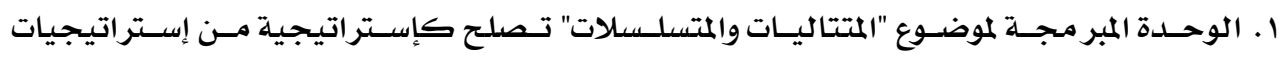

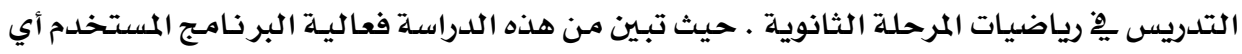

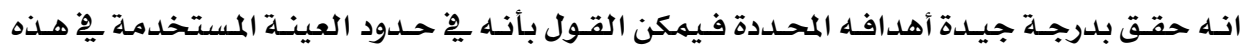

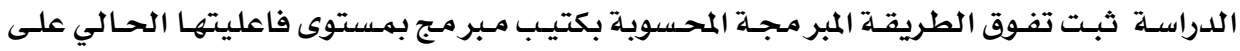

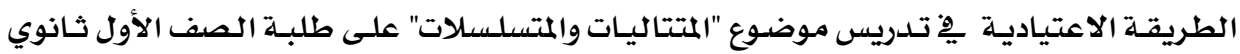

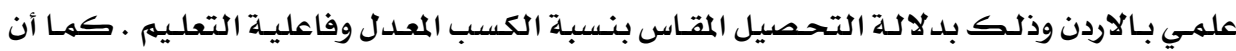

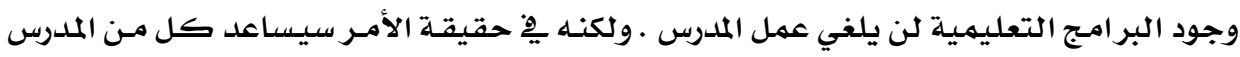

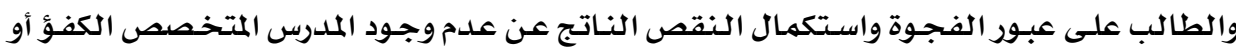

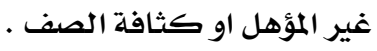

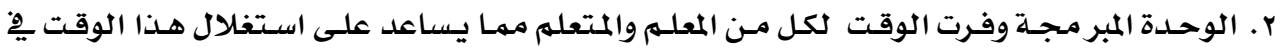

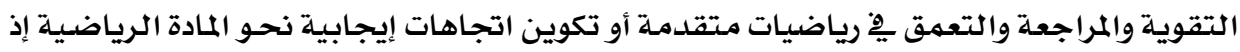




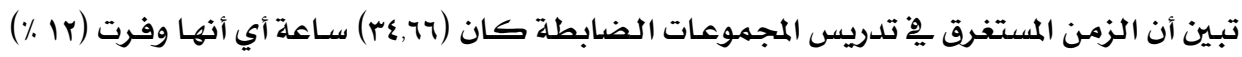

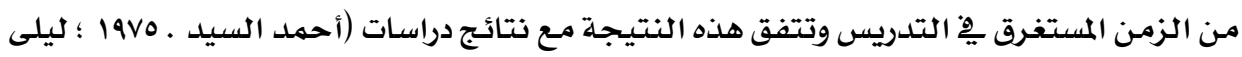

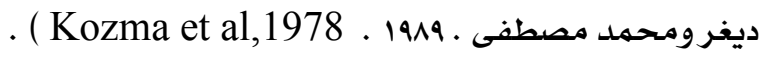

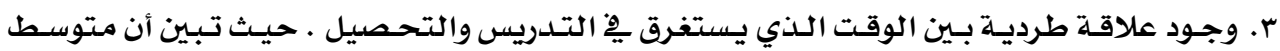

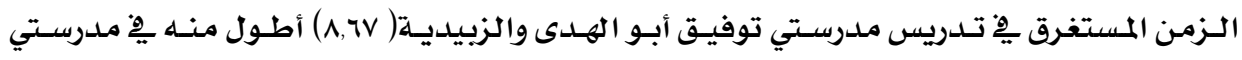

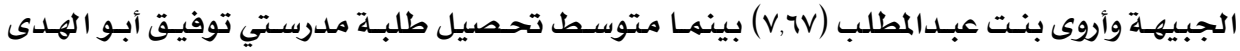

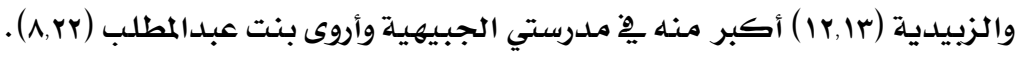

هقتزحات وتوصيات : مقديد

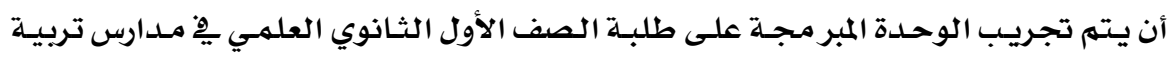

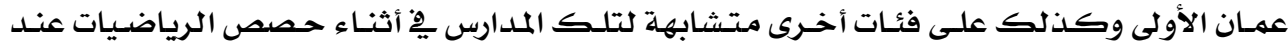

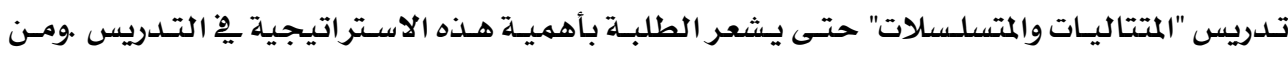

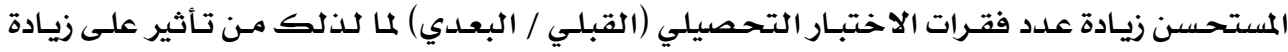
معامل ثبات الاختبار للوحدة الحالية . لمادئ.

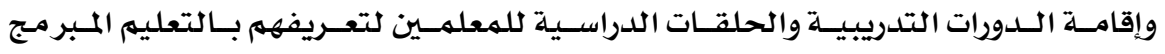

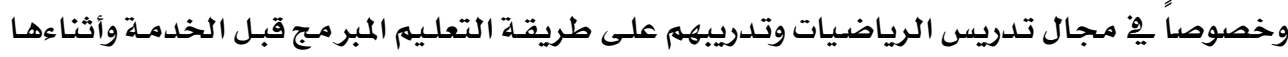

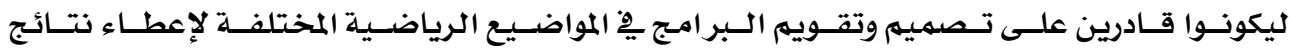

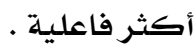

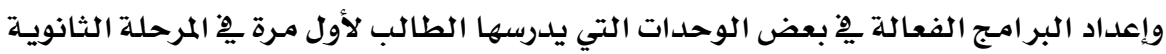

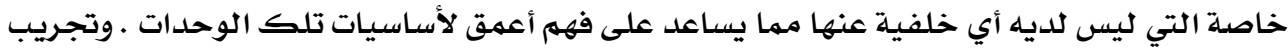

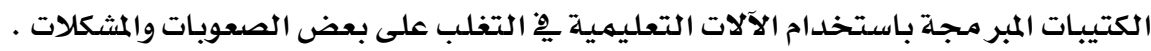




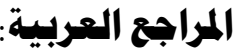

1- ابراهيم بسيوني عميرة وفتحي الذيب (r/911). تلدريس العلوم والتربية العلمية ، الطبعة السابعة ، مـصر :

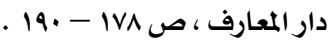

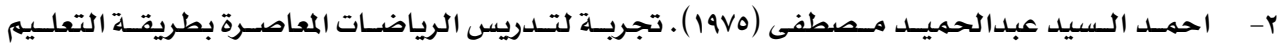

البرنـامسجي لطـلاب الـصف الاول مـن المرحلـة الثانويـة. رسـالة ماجسستير غـير منسشورة ، كليـة التربيسة ،

جامعة اسيوط.

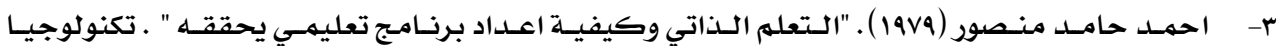

التعليه ، 7 (11): •r (11)

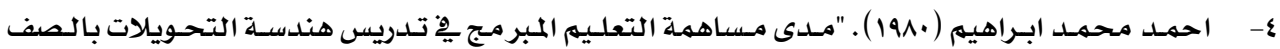

الثاني بالمرحلة الاعدادية " رسالة ماجستير غير منشورة جامعة المنصورة .

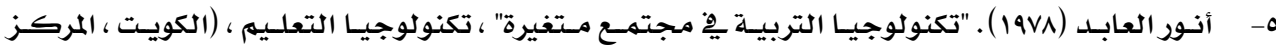

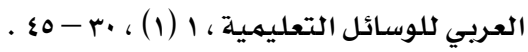

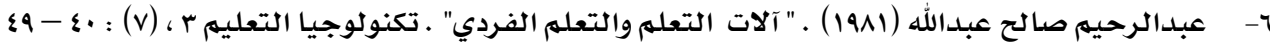

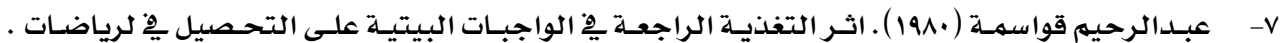

رسالة ماجستير ، جامعة اليرموك ، اريد .

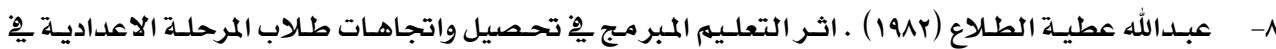

الاردن ِِّ مادة الرياضيات . رسالة ماجستير ، جامعة اليرموك، اريد.

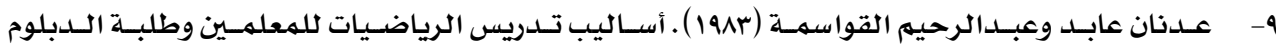

والكليات ، عمان: دار الفرقان.

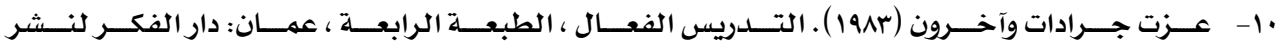

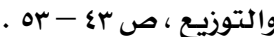

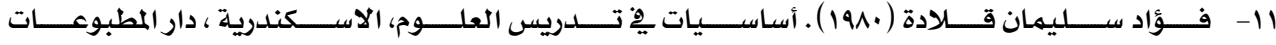

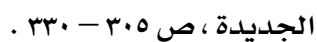

rا - ريد ابو زينـة (rA1 ) . الرياضيات منـاهجها واصول تدريسها ـ الطبعة الاولى عمان: دار الفرقان.

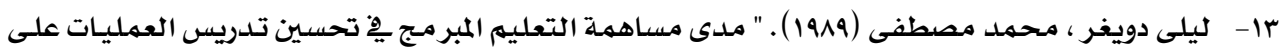

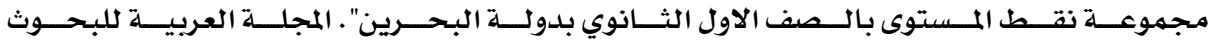

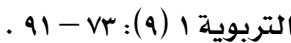

عا- وزارة التربية (1911) ـ المؤتمر الوطني الاول للتطوير التربوي ـ رسـالة المعلم. بديل العددين الثالث والرابـع

$$
\text { من المجلد التاسـع والعشرين. }
$$

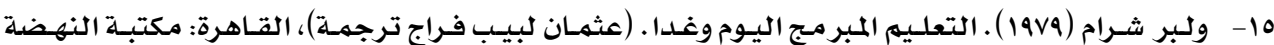

$$
\text { بمصر، ص .01-0 -010 }
$$

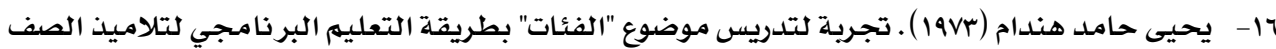
الثالث الاعدادي. القاهرة : دار النهضدة العربية ، ص VI - VI - . 


\section{References}

- Bloom, B. S. st al. (Eds) (1956). Taxonomy of Educational objectives. Handbook i: cognitive domain. New York: David Mckay Co. inc.

- Davis, T.N. (1967). "Transfer of Learning Gained in a Programmed Learning Task". Programmed Learning and Educational Psychology" 4 (1), 296-300 .

- Groundland , N.A. (1977). Constructing Achievement Tests. $\left(2^{\text {nd }}\right.$ Ed. ) Illinois: Prentice - Hall, P. 18

- Kozma, Rebert. B. et al. , (1978)." Instructional Techniques in in Higher Education", Educational Technology publications, Englewoodcliffs, new jersey.

- Lassa, Peter Ntasir. (1975). "A study of Mathematics programs for elementary school teachers in Nigeria", unpublished PH. D. Dissertation, university of Wisconsin Madison.

- Ofiesh, D.G. (1968). Programmed instruction: A Guide for Management, washingon, D.C. , National Education association and national society for programmed instruction. P. 338 .

- Roebuch, M. (1973) floundering among measurements in educational technology. In : aspects of educational technology. (Eds.) D. packhman (A. cleary, and T. Mayer, Bath, Pitman Press). Vol. 4, p. 473.

- Ronshausen, N.L. (1980). The Effects on Mathematics Achievement of Programmed Tutoring as a method of individualized one- To - one instruction. The journal of experimental education. 47 (4) : $269-276$.

- Skinner, b.F. (1968). "The technology of teaching". Appletion century crafts, pp. $64-66$. 